\title{
EDUCAÇÃO A DISTÂNCIA: POSSIBILIDADES NA FORMAÇÃO DE DOCENTES QUE ATUAM NA TUTORIA DE CURSOS SUPERIORES
}

\section{Michel da Costa ${ }^{1}$ \\ Maria Elisabette Brisola Brito Prado ${ }^{2}$ \\ Angélica Fontoura Garcia Silva ${ }^{3}$ Elisabeth dos Santos Tavares ${ }^{4}$}

\section{RESUMO}

A presente investigação é parte de uma pesquisa em desenvolvimento em nível de doutorado intitulada "Letramento Estatístico na Formação de Professores do Ensino Superior", inserida na linha de pesquisa "Formação de Professores" de uma Instituição de Ensino Superior privada, cujo campus localiza-se na capital do Estado de São Paulo. Os objetivos foram investigar questões acerca do conhecimento profissional dos docentes e suas práticas pedagógicas envolvendo conceitos da estatística, letramento estatístico e uso de projetos estatísticos como aprendizagem, sendo os participantes os cursistas de um curso de extensão universitária em serviço, realizada por docentes que exercem a função de tutoria em distintas áreas do conhecimento, tais docentes são pertencentes ao quadro de uma instituição privada de ensino superior localizada no Estado do Paraná. A formação continuada possibilitou ampliação dos conhecimentos relacionados ao letramento estatístico em diversas categorias definidas por Shulman como necessárias ao professor.

Palavras-Chave: Formação Docente; Educação a Distância; Ambiente Virtual.

\begin{abstract}
The presenter search is part of a doctoral level research entitled "StatisticalLiteracy in the Training of Teachersof Higher Education", which translates into teacher training of a Private Higher Education Institution, whose Campi is located in the capital of theStateof São Paulo, in Brazil. The objective swere to investigate the concept sofstatistics, learning and statistical projects as learning, and the participants of the

\footnotetext{
${ }^{1}$ Doutorando do Programa de Doutorado em Educação Matemática da Universidade Anhanguera de São Paulo. Professor Mestre da Universidade Metropolitana de Santos.

${ }^{2}$ Professora Doutora e Pesquisadora do Programa de Pós-Graduação Stricto Sensu em Educação Matemática da Universidade Anhanguera de São Paulo.

${ }^{3}$ Professora Doutora e Pesquisadora do Programa de Pós-GraduaçãoStricto Sensu em Educação Matemática da Universidade Anhanguera de São Paulo.

${ }^{4}$ Doutora pela Pontifícia Universidade Católica de São Paulo. Coordenadora do Núcleo de Educação a Distância da Universidade Metropolitana de Santos.
} 
university extension course in service, carried out byte achers who perform knowledge functions are typical of high er education, such teachers are part of a private high er education institution located in the State of Paraná. Continuing education en a bled the expansion of knowledge late to statistical education in several categories according to Shulman as necessary to the teacher.

Keywords: Training of Teachers; Distance Education; Virtual Environment.

\section{INTRODUÇÃO}

O presente artigo pretende compartilhar os primeiros resultados de uma pesquisa em desenvolvimento em nível de doutorado intitulada "Letramento Estatístico na Formação de Professores do Ensino Superior", inserida na linha de pesquisa "Formação de Professores" do Programa de Pós-Graduação em Educação Matemática de uma Instituição de Ensino Superior do Estado de São Paulo.

Essa pesquisa buscou investigar questões referentes ao conhecimento profissional docente e as práticas pedagógicas envolvendo conceitos da estatística, letramento estatístico e uso de projetos estatísticos como motores da aprendizagem, tendo como participantes da investigação os docentes de uma Instituição de Ensino Superior, localizada no Estado do Paraná, Todos atuam na tutoria de diferentes cursos na modalidade educação a distância - EaD, motivo pelo qual realizam a formação em serviço para afeiçoamento de suas atribuições.

Consideramos indispensáveis as discussões pertinentes à formação docente para os atuais desafios exigidos pela sociedade do século atual. Parece ser consenso que a formação dos profissionais que atuam no nível superior precisa ir além do conhecimento do conteúdo e de seus procedimentos, é necessário aliar esses saberes aos pedagógicos e curriculares, propiciando reflexões acerca da possibilidade de um fazer didático integrador que favoreça a participação ativa de seus alunos e a compreensão da realidade.

A escolha da temática "Letramento Estatístico", utilizada como cenário desse curso de extensão, deve-se ao fato de acreditarmos que a estatística está presente em todas as áreas do conhecimento, podendo ser uma fonte geradora de reflexão e discussão acerca da relação entre a teoria e prática no ambiente de aprendizagem, haja vista a importância da literacia estatística em diversos cenários de vida, bem como sua 
potencialidade de exploração da interdisciplinaridade e transversalidade nas atividades, pelos cursistas.

Sendo um recorte desse projeto maior de formação da instituição, essa pesquisa buscou elementos que respondam às seguintes questões: Qual é a importância da formação em serviço para os docentes que trabalham com a educação à distância? Quais as mediações esperadas pelos cursistas para que o curso apresente uma formação continuada de boa qualidade?

Portanto o nosso objetivo neste estudo é de compreender as contribuições da formação em serviço para docentes que atuam na $\mathrm{EaD}$.

Os objetivos desse trabalho estiveram centrados na compreensão de quais potencialidades de um curso de extensão na formação continuada de docentes que exercem o papel de tutor em cursos realizados na modalidade a distância, bem como identificar e analisar suas concepções acerca de formação docente, mediações pedagógicas proporcionadas pelos ambientes virtuais e de que forma o letramento estatístico pode favorecer o desenvolvimento de competências nesses docentes participantes do curso de extensão.

\section{REFERENCIAL TEÓRICO}

A formação docente continuada e permanente é fundamental para a própria atualização, melhoria de suas práticas e troca de experiências com seus pares. Embora esses itens sejam relevantes, consideramos que também seja importante pensarmos nos conhecimentos necessários para suas efetivas práticas educativas, tal como afirma Imbernón (2014).

Shulman (1986) verificou que os conhecimentos necessários ao docente tinham como premissas o agrupamento de habilidades, conhecimentos disciplinares e pedagógicos necessários à realização das atribuições dos professores num determinado contexto de ensino, Realizou no fim dos anos 1980 um estudo de caso, visando à compreensão dessas questões. Para esse autor, a visão do processo de ensino não pode se confundir com a visão restrita de que a educação é a transmissão do conhecimento por meio de um professor ativo a um aluno passivo. No contexto da educação a distância podemos refletir sobre a necessidade de transgredir os processos de ensino e 
aprendizagem que precisam ser dinâmicos e constantemente atualizados, não podendo ser meros repositórios de conteúdos, pois o processo educativo é amplo e complexo.

Desses estudos, Shulman (1986) categorizou a base de conhecimentos e em pesquisas recentes Shulman (2014) ampliou as iniciais para sete subdivisões: conhecimento do conteúdo, conhecimento pedagógico geral, conhecimento curricular, conhecimento pedagógico do conteúdo, conhecimento dos alunos, conhecimento de contextos educativos e conhecimento de fins educacionais.

Há um destaque para a categoria "conhecimento pedagógico do conteúdo" pela relação direta entre o conteúdo e o ensino, pertinente às atribuições do docente.

Os estudos que tratam do letramento estatístico, assim como aqueles que discutem as diferentes categorias de conhecimentos para o ensino, baseado nas ideias de Shulman (1986, 2014), as quais foram ampliadas pelos estudos de Batanero (2002) referentes aos conhecimentos pedagógicos da estatística, constituem referências importantes para repensar a formação do professor no que tange ao Letramento Estatístico.

Nessa perspectiva vale ressaltar a necessidade do professor que vai lecionar, independente da disciplina, há necessidade do letramento estatístico, já que tais competências são necessárias ao exercício pleno da cidadania, pois dados estão presentes em distintos contextos e áreas do conhecimento.

Nesse panorama, utilizamos Gal (2004) ao afirmar que o letramento estatístico está associado a dois componentes inter-relacionados, sobretudo:

(a) a capacidade das pessoas para interpretar e avaliar criticamente a informação estatística, os argumentos relacionados a dados, ou fenômenos estocásticos, que eles podem encontrar em diversos contextos, e identificar sua relevância;

(b) a sua capacidade para discutir ou comunicar as suas reações a estas informações estatísticas, tais como a sua compreensão do significado das informações, as suas opiniões sobre as implicações desta informação, ou as suas preocupações em relação à aceitabilidade dos dados conclusões. (GAL, 2004, p. 49)

Assim, consideramos que é de fundamental importância para o profissional que pretende ensinar estatística receber uma formação adequada. Uma formação que lhe permita interpretar e avaliar criticamente as informações estatísticas apresentadas, assim como a comunicar e discutir tais informações. 
Além disso, para compreender o processo de aprendizagem da docência no âmbito geral apoiar-nos-emos em estudos de Shulman (1986, 1987, 2014), nos quais discute o conhecimento pedagógico da matéria a ser ensinada, partindo de análises referentes ao "pensamento do professor" e ao "conhecimento do professor". Em seus primeiros estudos, já chamava a atenção para o que ele havia identificado como o "paradigma perdido" - o conhecimento do conteúdo -, destacando a necessidade do domínio deste para o ensino da disciplina. E, partindo da constatação de que as pesquisas ignoravam o conteúdo específico lecionado e não investigavam “... como o conteúdo específico de uma área de conhecimento era transformado a partir do conhecimento que o professor tinha em conhecimento de ensino", essa investigação estará restrita a três das categorias elencadas por Shulman:

Conhecimento do conteúdo: refere-se a conteúdos específicos da disciplina que o professor vai ensinar, pois seria impossível ensinar algo que ainda não domina no seu próprio campo cognitivo, incluindo as próprias crenças e justificativas do porquê está ensinando tais conteúdos.

Conhecimento pedagógico de conteúdo: corresponde a uma intersecção entre o conteúdo a ensinar e a pedagogia que pertence unicamente aos professores, e que constitui a sua forma especial de compreensão de como tópicos particulares, problemas ou temas são organizados, representados e adaptados aos interesses e capacidades dos alunos e apresentados para o ensino.

E a terceira categoria utilizada: Conhecimento curricular, sendo considerado o conhecimento sobre as alternativas curriculares possíveis para o ensino, ou seja, é o conhecimento dos materiais curriculares alternativos para um determinado conteúdo, que inclui conhecimentos de teorias e princípios relacionados ao processo de ensino e aprendizagem.

Dentre essas categorias, o conhecimento pedagógico do conteúdo é a que mais tem se destacado em pesquisas que discutem a formação docente e prática educativa, pois trata-se de um conhecimento amplo, uma combinação entre o conhecimento da matéria e o modo de ensiná-la:

Entre essas categorias, o conhecimento pedagógico do conteúdo é de especial interesse, porque identifica os distintos corpos de conhecimento necessários para ensinar. Ele representa a combinação de conteúdo e pedagogia no entendimento de como tópicos específicos, problemas ou questões são 
organizados, representados e adaptados para os diversos interesses e aptidões dos alunos, e apresentados no processo educacional em sala de aula. O conhecimento pedagógico do conteúdo é, muito provavelmente, a categoria que melhor distingue a compreensão de um especialista em conteúdo daquela de um pedagogo. Embora se possa dizer muito mais sobre as categorias da base de conhecimento para o ensino, elucidá-las não é o principal propósito deste ensaio. (SHULMAN, 2014, p. 207)

Trata-se de um conhecimento de fundamental importância nos processos de aprendizagem, posto ser ele o único conhecimento em que o professor é o verdadeiro protagonista. A esse respeito Batanero (2002) citando Shulman e um estudo de sua coautoria (Godino, Batanero e Flores, 1999) descreve como componentes básicos desse Conhecimento Pedagógico da Estatística:

- A reflexão epistemológica sobre o significado de conceitos, procedimentos
(geralmente objetos) tem como objetivo ensinar os indivíduos, ou seja, neste
caso, a reflexão epistemológica sobre a natureza do conhecimento
estocástico, o seu desenvolvimento e evolução.

- Análise das transformações do conhecimento para se adaptar a diferentes níveis de ensino. Esta análise permite refletir sobre os diversos níveis possíveis de compreensão sobre o mesmo conhecimento e avaliar o nível e, particularmente, como um conceito particular poderia ser ensinado a uma pessoa em particular.

- Estudo sobre as dificuldades, os obstáculos e os erros dos alunos na aprendizagem e estratégias de resolução de problemas que irão orientar melhor o trabalho de ensino e avaliação de aprendizagem.

- Análise de currículo, ensinando situações, ensinando metodologia para temas específicos e recursos pedagógicos específicos. Isso faz parte dos recursos metodológicos para melhorar a ação educativa. (BATANERO, 2002, p. 95)

Consideramos, assim como esses autores, haver inúmeras expectativas sobre o perfil dos professores que utilizarão o letramento estatístico em suas práticas, todavia é fundamental que compreendam essa temática com tal profundidade que lhes permita representá-la apropriadamente sob múltiplas formas, utilizando-se de metodologias diversificadas, levando em conta a reflexão epistemológica, a organização do conteúdo para os diferentes níveis de ensino, além da preocupação com as dificuldades encontradas no trabalho pedagógico com seus alunos. 


\section{PROCEDIMENTOS METODOLÓGICOS}

O presente projeto de pesquisa de natureza qualitativa buscou por meio dos dados coletados responder às questões da pesquisa e compreender o impacto da formação proporcionado aos cursistas.

Participaram do curso o total de 395 docentes distribuídos em seis grupos, sendo essa investigação delimitada a um grupo com 52 cursistas.

Embora em muitas pesquisas prevaleçam às técnicas convencionais que se preocupam com a quantificação de resultados empíricos, o presente projeto valorizou a participação, compreensão, interação e ações planejadas entre o pesquisador e os grupos de participantes, algumas dessas técnicas foram realizadas nos encontros presenciais e outras no ambiente virtual.

Nessa fase investigatória e de coleta de dados os participantes da pesquisa, professores cursistas, assumiram um papel importante fornecendo respostas não em função das expectativas do pesquisador, mas sim através de uma reflexão individual ou coletiva a respeito das atividades investigativas vivenciadas no curso, onde responderam um formulário com a finalidade de diagnosticar o perfil dos participantes, bem como alguns conhecimentos básicos que possuem acerca da educação à distância e referente ao letramento estatístico em diferentes contextos, tanto nos aspectos do cotidiano quanto nos profissionais.

Os procedimentos para o desenvolvimento da pesquisa envolvem primeiramente o levantamento do perfil dos participantes, e em seguida realização de oficinas. As oficinas foram organizadas em quatro encontros presenciais e 120 horas na modalidade à distância, tendo a participação de 395 professores que atuam em cursos diversos do Ensino Superior.

Cada encontro teve em média duas horas de duração, em que foram utilizados protocolos de atividades dos participantes e registros gravados em áudio, bem como o diário de campo do pesquisador.

A pesquisa foi realizada, utilizando os dados coletados nos encontros presenciais e os diretamente do ambiente virtual, sempre com o caráter de contribuir com a educação, não tendo a intenção de expor pessoas ou fatos ocorridos durante o curso. 


\section{ANÁLISE DOS DADOS E DISCUSSÃO}

O questionário inicial dos participantes dessa pesquisa demonstrou que a maioria dos docentes $(67,3 \%)$ que já atuam na educação a distância nunca realizaram cursos na modalidade à distância. Dessa forma consideramos que o curso é primordial à formação desses docentes, já que a vivência no ambiente virtual enquanto alunos é bastante relevante para a compreensão dos fatores que Prado (2006) indica na composição da mediação pedagógica com uso de recursos tecnológicos, sendo esses: material, atividades e interações.

Quanto às suas expectativas na participação do curso, foram obtidas respostas positivas, como indica a tabela 1, a seguir:

\section{Tabela 1 - Expectativas Iniciais dos Cursistas}

\begin{tabular}{lr}
\hline Expectativa & Quantidade \\
\hline Ampliar/Adquirir novos conhecimentos & 25 \\
Formação Acadêmica para Preparação do Mestrado/ & 3 \\
Doutorado & 2 \\
Auxiliar na Publicação de Artigos & 8 \\
Estabelecer relações com a área de atuação & 4 \\
Melhorar as aulas e utilizar estatística & 9 \\
Necessária a formação continuada/em serviço & 1 \\
Nenhuma & 52 \\
\hline Total & \\
\hline
\end{tabular}

Fonte: Acervo da Pesquisa

Nos encontros presenciais, alguns depoimentos foram relevantes no sentido de indicarem que a temática Letramento Estatístico não seria mero cenário, e vários dos participantes com formações distintas, afirmaram que passaram a transgredir os conteúdos de suas disciplinas e também a usá-lo fora do ambiente educacional, como evidenciam:

O Curso me fez considerar que as ideias de letramento estatístico estão presentes em diversas áreas do conhecimento, inclusive, na minha formação (letras), onde posso utilizar a leitura e interpretação de tabelas e gráficos para auxiliar meus alunos na tomada de decisões. (Cursista 27, 43 anos, formação em Letras) 
Senti bastante dificuldade no início do curso, pois associava a estatística à matemática. Mas, percebi o quanto é relevante para minha área do serviço social: fazer a leitura com compreensão de tabelas e diferentes gráficos... alguns dos quais eu nem conhecia. Certamente usarei mais em minhas práticas educativas e também na minha vida. (Cursista 38, 48 anos, formação em Serviço Social)

Nos depoimentos acima, podemos utilizar as relações existentes entre duas das categorias de Shulman: conhecimento da matéria a ser ensinada e conhecimento pedagógico do conteúdo, pois demonstram a necessidade de conhecer os conteúdos da estatística e também a preocupação na utilização das práticas docentes. Tais depoimentos remetem a uma reflexão acerca de como os docentes utilizariam os conhecimentos do letramento estatístico se ainda não tinham os mesmos consolidados?

Apesar de não serem especialistas da área de matemática, tampouco estatística, no geral, percebemos uma grande satisfação com os depoimentos como os acima, bem como as interações no ambiente virtual, em uma atividade que utilizava as ideias acerca das medidas estatísticas de tendência central envolvendo os princípios de transversalidade e interdisciplinaridade para que os cursistas refletissem sobre a resolução da situação-problema exposta e também fizessem relação com a área de conhecimento de sua formação.

Em minha opinião, visto que o exemplo sugerido busca avaliar o sedentarismo em idosos [...] como enfermeira, poderia utilizar a mediana para avaliar a faixa etária dos pacientes atendidos na unidade de atendimento médico. A partir dessa análise seria possível identificar desde o paciente mais novo até o mais velho. (Cursista 49, 52 anos, Curso de Enfermagem)

Nesse panorama indicado pelo depoimento acima, percebemos que a adaptação dos conteúdos do Letramento Estatístico aos currículos dos cursos em que esses docentes atuam, também indica a categoria de Shulman em que o professor precisa ter o conhecimento curricular para as possíveis utilizações, como ilustra o fragmento presente em um fórum acerca das medidas estatísticas de tendência central.

\section{CONSIDERAÇÕES FINAIS}

A pesquisa possibilitou reforçar a necessidade de formação continuada, preferencialmente em serviço, dos professores que atuam no Ensino Superior, sendo necessário aos que atuam no ambiente virtual que vivenciem experiências como aluno. 
No decorrer do curso, foi possível compreender o processo de construção do letramento estatístico, que cada vez mais se aproxima dos conteúdos do curso e perceber que a estatística é necessária à formação do cidadão, tendo em vista a crescente utilização de seu conhecimento em áreas distintas do saber e também nos ambientes não-escolares.

Dessa forma, percebemos que o curso contribuiu com a formação desses professores que atuam na tutoria do ambiente virtual e que possivelmente utilizarão os conhecimentos do letramento estatístico em suas distintas atuações pedagógicas como forma de enriquecimento curricular, bem como recurso diferenciado de linguagem.

Por meio dos depoimentos dos cursistas no ambiente virtual e nos encontros presenciais, percebemos que os tipos de atividades propostas propiciaram aos participantes significar e relacionar o letramento estatístico com suas áreas de conhecimento.

Dessa forma, percebemos que os participantes demonstraram desenvolvimento na categoria conhecimento pedagógico do conteúdo, pois trouxeram elementos para suas próprias práticas educativas com novos olhares para a atuação profissional e utilizando os conteúdos de estatística em seus contextos de áreas específicas, desvelando uma visão transdisciplinar e interdisciplinar do conhecimento.

\section{REFERÊNCIAS BIBLIOGRÁFICAS}

BATANERO, C. Didáctica de la Estadística.Universidad de Granada.

Departamentode Didáctica de la Matemática, 2001. Disponível em na .http://www.ugr.es/ batanero. Acesso em 27 nov.2014.

BATANERO, C. Estadística y didáctica de la matemática: Relaciones, problemas y aportaciones mutuas. Em: Penalva, C. Torregrosa, G..y Valls, J. (Eds.), Aportaciones de la didáctica de la matemática a diferentes perfiles profesionales. Alicante (ES): Universidad de Alicante, 2002, pp. 95-120.

D’AMBRÓSIO, U. Reflexões sobre conhecimento, currículo e ética.In:MACHADO,N. J.; D’AMBRÓSIO, U. (Orgs). Ensino de Matemática. São Paulo: Summus, 2014. 
GAL, I. Statistical literacy: meanings, components, responsibilities. In: Ben-Zvi, D. \& Garfield, J.(Eds). The challenge of developing statistical literacy reason and trinking. The Netherlands: Kluwwer, 2004, p. 47-78.

GAL, I. Adults Statistical Literacy: meaning, components, responsibilities. International Statistical Review, The Netherlands v. 70, n.1, 2002, p. 125.Disponível em: http://iase-web.org/documents/intstatreview/02.Gal.pdf Acesso em 10 mai. 2016.

GODINO, J. D., BATANERO, C. Y FLORES, P. El análisis didáctico del contenido matemático como recurso en la formación de profesores. En: Homenaje al profesor Oscar Sáenz Barrio. Granada: Departamento de Didáctica y Organización Escolar, 1999, p. 165-185. (1999).

IMBERNON, F. Formação permanente do professorado: novas T tendências. São Paulo: Cortez, 2014.

PRADO, Maria ElisabetteBrisola Brito. Educação a distância e formação do professor: redimensionando concepções de aprendizagem - Tese de Doutorado da Pontifícia Universidade Católica de São Paulo (PUC), São Paulo, 2003.

SHULMAN, L. S. Knowledge and teaching: foundations of the new reform. Harvard Educational Review, v.57, n.1, 1987, p. 1-22.

SHULMAN, L. S. Those who understand: Knowledge growth in teaching. Educational Researcher.v.15, n.2, 1986, p. 4-14.

SHULMAN, L. S. Conhecimento e ensino: fundamentos para a nova reforma. In Cadernos CENPEC, São Paulo, v.4, n.2, p. 196-229, 2014. Disponível em: http://cadernos.cenpec.org.br/cadernos/index.php/cadernos/article/view/293/297 Acesso em 12 jan. 2018 


\section{Michel da Costa}

Doutorando do Programa de Doutorado em Educação Matemática da Universidade Anhanguera de São Paulo. Professor Mestre da Universidade Metropolitana de Santos

\section{Maria Elisabette Brisola Brito Prado}

Professora Doutora e Pesquisadora do Programa de Pós-Graduação Stricto Sensu em Educação Matemática da Universidade Anhanguera de São Paulo

\section{Angélica Fontoura Garcia Silva}

Professora Doutora e Pesquisadora do Programa de Pós-GraduaçãoStricto Sensu em Educação Matemática da Universidade Anhanguera de São Paulo.

\section{Elisabeth dos Santos Tavares}

Doutora pela Pontifícia Universidade Católica de São Paulo. Coordenadora do Núcleo de Educação a Distância da Universidade Metropolitana de Santos.

Artigo recebido em 27/06/2019

Aceito para publicação em 29/07/2019

\section{Para citar este trabalho:}

COSTA, Michel da; PRADO, Maria Elisabette Brisola Brito; SILVA, Angélica Fontoura Garcia; TAVARES, Elisabeth dos Santos. EDUCAÇÃO A DISTÂNCIA: POSSIBILIDADES NA FORMAÇÃO DE DOCENTES QUE ATUAM NA TUTORIA DE CURSOS SUPERIORES.Revista Paidéi@. Volume 11 - Número 20 - JULHO - 2019 - Disponível em: 